\title{
Ciencia y tecnologia para el desarrollo
}

El conocimiento científico, en su indagación sobre las leyes de la naturaleza y los comportamientos sociales, es una de las más altas expresiones del espíritu humano. Asociado con la tecnología es también un instrumento indispensable para el desarrollo de las sociedades contemporáneas. La prosperidad de los países depende en gran medida del valor que agrega el conocimiento a la producción de bienes y servicios. Para denominar a este proceso se han acuñado expresiones tales como "sociedad del conocimiento" y "economía del conocimiento", con las que se pretende caracterizar la época actual y mostrar las oportunidades y desafios que surgen de las aplicaciones productivas de la ciencia y la tecnología.

Es así que el éxito en el camino hacia el desarrollo depende en buena medida de la capacidad de gestionar el cambio tecnológico aplicado a la producción, la explotación racional de los recursos naturales, la protección del medio ambiente, el cuidado de la salud, la alimentación, la educación y la atención de otros requerimientos sociales. La brecha entre países ricos y pobres no remite sólo a una distribución desigual de la riqueza, sino también del conocimiento. Por ello, las políticas de ciencia, tecnología e innovación, así como las de educación, se han convertido en herramientas imprescindibles para el logro de una mayor equidad.

La estrategia de industrialización sustitutiva de importaciones que muchos países latinoamericanos pusieron en práctica a partir de los años cincuenta tuvo en cuenta la importancia de la ciencia y la tecnología. Tanto fue así, que en muchos países de América Latina se generó además un "pensamiento" propio en lo referido a las relaciones entre ciencia, tecnología y desarrollo. Es verdad que no se trató de una corriente uniforme, ya que muchas de aquellas visiones eran discordantes y hasta antagónicas, pero tuvieron el mérito de instalar en la agenda pública la necesidad de impulsar la ciencia y la tecnología como instrumentos para el desarrollo. La más célebre de aquellas contribuciones fue la del "triángulo de las Interacciones" propuesto por Jorge Sabato y Natalio Botana, que postulaba la necesidad de fortalecer los vínculos entre el gobierno, los centros académicos y las empresas. Este esquema es todavía útil actualmente para pensar la relación entre

http://dx.doi.org/ 10.18004/riics.2015.diciembre.161-163 
ciencia, política y desarrollo. Es cierto que la experiencia latinoamericana de impulsar el desarrollo con ciencia y tecnología propia no podría ser considerada globalmente como un éxito, pero también es cierto que tuvo logros destacados en campos estratégicos tales como la energía nuclear, el desarrollo de satélites, la industria aeronáutica, la salud y la tecnología agropecuaria, entre otros.

Una buena noticia es que en los últimos años los gobiernos de América Latina vienen intensificando su apoyo a la investigación científica y el desarrollo tecnológico. Actualmente se ha generalizado el consenso entre gobiernos y opinión pública acerca de la necesidad de aplicar políticas de ciencia, tecnología e innovación para lograr un desarrollo equitativo y sustentable. Es urgente profundizar este rumbo, ya que el logro de un perfil productivo con mayor valor agregado, que cambie el perfil de las exportaciones, continúa siendo un desafio en la región. No se trata solamente de estimular la producción, sino también de buscar soluciones para muchos problemas sociales acuciantes que esperan todavía ser resueltos. No es posible ignorar que hay una brecha social muy profunda en el acceso a los bienes materiales, culturales y a los servicios básicos, lo que constituye un apelativo ético al conjunto de las sociedades latinoamericanas.

Las ciencias sociales pueden aportar mucho para comprender la magnitud del problema de la inequidad en la distribución del ingreso, caracterizarlo correctamente, desentrañar los mecanismos que están en juego y proponer líneas de acción posibles. Las tecnologías inclusivas tienen un importante papel en las políticas sociales. Con un enfoque interdisciplinario, la ciencia brinda también los conocimientos adecuados para el cuidado del ambiente y la explotación sustentable de los recursos naturales.

Para lograr avances significativos en todos estos planos es preciso sumar capacidades a través de la cooperación regional, ya que ningún país puede ser autosuficiente en ciencia y tecnología. También es necesario disponer de sistemas avanzados de información científica y tecnológica, a fin de hacer tareas de inteligencia estratégica que permitan evaluar tendencias e identificar nuevas tecnologias disponibles. La madurez científica y tecnológica de un país implica la capacidad de crear conocimiento de excelencia, pero también de obtenerlo de fuentes adecuadas, difundirlo y aplicarlo.

Nada de esto sería posible si los países latinoamericanos no dispusieran de profesionales, científicos y tecnólogos capacitados para crear nuevo conocimiento a través de la investigación científica y el desarrollo tecnológico, así como para 
obtener conocimiento generado en fuentes externas. En ambos casos, deben estar capacitados para adaptarlo y transferirlo a los actores de las tramas productivas y sociales. Esto resalta el importante papel que corresponde a las instituciones educativas $\mathrm{y}$, en particular, a las universidades. Una cultura cientifica y tecnológica ampliamente extendida en la población es también una condición necesaria para dar impulso a la vinculación entre quienes producen, identifican, adaptan y aplican los conocimientos con la mirada puesta en el logro de un desarrollo sustentable en términos sociales y ambientales.

\section{Mario Albornoz}

Coordinador del Observatorio Iberoamericano de la Ciencia,la Tecnología y la Sociedad, de la OEI 